\title{
NUMERICAL SOLUTIONS OF COASTAL MORPHODYNAMIC EVOLUTION FOR COMPLEX TOPOGRAPHY
}

\author{
Chiang Yun-Chih \\ Center for General Education, Tzu Chi University, Taiwan, R.O.C., sshsiao@mail.ntou.edu.tw \\ Hsiao Sung-Shan \\ Department of Harbor and River Engineering, National Taiwan Ocean University, Taiwan, R.O.C \\ Lin Ming-Chung \\ Department of Engineering Science and Ocean Engineering, National Taiwan University, Taiwan, R.O.C.
}

Follow this and additional works at: https://jmstt.ntou.edu.tw/journal

Part of the Civil and Environmental Engineering Commons

\author{
Recommended Citation \\ Yun-Chih, Chiang; Sung-Shan, Hsiao; and Ming-Chung, Lin (2010) "NUMERICAL SOLUTIONS OF COASTAL \\ MORPHODYNAMIC EVOLUTION FOR COMPLEX TOPOGRAPHY," Journal of Marine Science and Technology. Vol. 18: \\ Iss. 3, Article 2. \\ DOI: 10.51400/2709-6998.1878 \\ Available at: https://jmstt.ntou.edu.tw/journal/vol18/iss3/2 \\ This Research Article is brought to you for free and open access by Journal of Marine Science and Technology. It has been \\ accepted for inclusion in Journal of Marine Science and Technology by an authorized editor of Journal of Marine Science and \\ Technology.
}




\title{
NUMERICAL SOLUTIONS OF COASTAL MORPHODYNAMIC EVOLUTION FOR COMPLEX TOPOGRAPHY
}

\author{
Yun-Chih Chiang*, Sung-Shan Hsiao**, and Ming-Chung Lin***
}

Key words: numerical modeling, morphodynamic evolution, sediment conservation law, oscillation removal.

\begin{abstract}
Numerical modeling of coastal morphodynamic evolution is a powerful tool for the planning and design of coastal engineering. The coastal morphological modeling system is based on the sediment conservation law, which couples modules for waves, wave-driven currents, and sediment transport rates. The numerical scheme for the sediment conservation law and nonlinear coupling between these modules can lead to dispersions, diffusions, spurious oscillations and stability problems that are still not well developed. In this paper, the bedslope updating techniques, oscillation removal schemes, and 2-step, 3-time-level temporal discretization are employed to avoid oscillations and improve the stability of the coastal morphological model with accuracy up to $O\left(\Delta t^{2}, \Delta x^{5}, \Delta y^{5}\right)$. Finally, the model shows good performance for coastal areas with complex topography.
\end{abstract}

\section{INTRODUCTION}

Coastal morphological models are indispensable and powerful tools that allow harbor and hydraulic engineers to predict nearshore topography, to analyze the impact of coastal structures, and to verify the planning and design of harbors and coastal defenses. Morphological models are based on various sub-models for waves, tidal currents, nearshore currents, and sediment transport, coupled with the sediment transport model. The sediment transport model solves the sediment conservation equation to calculate bed-level evolution. The local sediment transport is first calculated by wave and current sub-models, and the bed form evolution is then computed

Paper submitted 04/07/09; revised 06/05/09; accepted 06/10/09. Author for correspondence: Sung-Shan Hsiao (e-mail: sshsiao@mail.ntou.edu.tw). *Center for General Education, Tzu Chi University, Taiwan, R.O.C.

**Department of Harbor and River Engineering, National Taiwan Ocean University, Taiwan, R.O.C.

***Department of Engineering Science and Ocean Engineering, National Taiwan University, Taiwan, R.O.C. based on the conservation of sediment and its continual redistribution in time. In the last twenty years, two dimensional depth-averaged coastal morphological models have been developed, and these models have been applied in the short-term (hours to days) and medium-term (months to years) $[1,6,10$, $26,35,40,43,44]$.

In these morphodynamic systems, the governing equations are a nonlinear function of bed level. The sediment transports, which are caused by waves and currents, are also calculated from complicated nonlinear hydrodynamic systems. The nonlinear couplings and numerical scheme errors in these sub-models can generate unstable and inaccurate numerical results, whose natures are still poorly understood. Even though the results of all sub-models are accurate and robust, their combination in the sediment conservation equation also leads to numerical oscillations and instabilities [17]. They generally fail to accurately predict the bed form evolution in surf zone and in the areas around coastal structures for long term simulations [21]. Several techniques to improve accuracy and stability for coastal morphological modeling have been developed in the last decades. The main concern of these studies is to stabilize the solutions when solving the sediment conservation equation. As reviewed in Long et al. [24], many state-of-the-art models introduce oscillation controlling schemes for bed form evolution modeling. The Delft Hydraulics model Delft2D-MOR [30, 31] utilizes a forward time, central space explicit scheme with a corrected sediment transport rate to offset the negative diffusion terms in the scheme. The University of Liverpool model $[27,28]$ uses a two-step Lax-Wendroff scheme considering the effects of gravity on the bed slope for sediment transport rates. Vincent and Caltagirone [39] also use a modified Lax-Wendroff scheme with the Total Variation Diminishing scheme (LWTVD) and a slope limiter. Cayocca [4] uses a forward-time upwind scheme with the transport rate corrected due to the effect of the bed form slope $[7,8]$ and an input filtering technique $[10,11]$ to prevent oscillation. Johnson and Zyserman [21] illustrate that the bed form slope plays a principal role in the instability of morphological numerical schemes and expands a second order Taylor-Series of the bed level in time: the first order time derivative term is composed of the sediment conservation equation calculated with the Lax-Wendroff 
scheme, and the second order time derivative term is regarded as the diffusion terms of advection equation. Their morphological scheme is also modified with a low-pass filter to dissipate spurious high frequency oscillations (Jensen et al.) [17]. Saint-Cast [33] applied the high-resolution NOC (NonOscillating Centered) scheme (Jiang and Tadmor) [18] and bedform slope updating technique (suggested by Watanabe) [42] to solve the sediment conservation equation without a filter or limiter. Shao et al. [35] and Long et al. [24] utilized the WENO (Weighted Essentially Non-Oscillatory) algorithm from the Computational Fluid Dynamics scheme [20, 23] to solve the $1 \mathrm{D}$ and $2 \mathrm{D}$ sediment conservation equation without any filters or limiters.

More recently, the advantages and disadvantages of these controlling oscillatory morphological models were reviewed. Several numerical schemes are reviewed by Callaghan et al. [3], including a first order upwind scheme, two Lax-Wendroff schemes [21, 39] and the NOC scheme (Saint-Cast) [33]. Long et al. [24] review two Lax-Wendroff schemes (the Richtmyer scheme and the MacCormack scheme) and two WENO schemes (the TVD-RK-WENO scheme by Shao et al. and the Euler-WENO scheme by Long et al.) [35, 24]. According to these reviewed results, Lax-Wendroff schemes or modified Lax-Wendroff schemes for morphodynamic system are not stable for long term simulation of bed level evolution. The filter, limiter, or artificial viscosity should be added to prevent numerical oscillation in these schemes. They also found that it is difficult to determine the phase celerity of the bed form, which is the most important parameter for the scheme's stability, when these weakened morphological schemes are applied to complex bathymetry. Among the reviewed schemes, the NOC and WENO schemes are stable and easy to use; they do not need any filters or limiters and do not require accurate phase celerity of the bed form. They apply the NOC and WENO schemes successfully for the cases of a 1D sand bar deformation due to waves on even bottom, the 2D open channel periodic fluctuating bottom deformation due to a constant flux, and idealized river entrance topography changes, perpendicular to a straight beach with a mild slope under irregular directional waves. However, there are few studies that prevent oscillations successfully for morphodynamic schemes applied to the complex topography of a coastal area under monsoon waves for long term simulations.

The aim of the present work is to develop a model that is able to calculate the change in coastal topography for long term simulations under waves and wave-driven currents. Therefore, the model should not only be able to control the oscillations in space, but also improve the accuracy in time. The model should also take into account the effects caused by the discontinuity of the contours and beach slopes. The model presented here is based on the high-order WENO scheme. In this paper, we analyze the diffusion of the sediment conservation equation, bed-level evolution schemes and sub-models, such as wave models, wave-driven current models, and sediment transport rate models. In order to achieve high stability and accuracy, some methodologies have been adapted, which include feedback from the bed-slope at every time step, WENO schemes, and multi-time-level techniques. To demonstrate the performance, we apply the model to two examples with complex bathymetry in Taiwan, investigate its stability and performance and compare our scheme with the FTCS and Euler-WENO schemes. In the first example, complex multislope beach topography is examined. The other example tested the model for a steep slope and convex topography.

\section{OSCILLATIONS REDUCTION IN MORPHOLOGICAL MODEL}

\section{Conservation of Sediment Transport}

The change of bed form in local bottom elevation $z_{b}$ can be computed by solving the conservation equation for sediment mass. In two dimensions, this can be written as:

$$
\frac{\partial}{\partial t}\left[(1-n) z_{b}+\int_{z_{b}}^{\eta} c d z\right]+\left(\frac{\partial q_{x}}{\partial x}+\frac{\partial q_{y}}{\partial y}\right)=0
$$

where $z_{b}$ is the bed level elevation, defined as positive up from a fixed datum, $x$ and $y$ are horizontal space coordinates, $t$ is time, $n$ is the bed porosity, $\eta$ is the free surface elevation, $\mathrm{c}$ is the suspended sediment concentration in the water column per unit area, and $q_{x}$ and $q_{y}$ are the total volumetric sediment transport rates (unit: $\mathrm{m}^{3} / \mathrm{sec}$ ) in the $x$ - and $y$ - directions, respectively.

In general, the suspended load contribution of sediment can be consisted in sediment flux, and the sediment transport conservation equation can be reduced to:

$$
\frac{\partial z_{b}}{\partial t}+\frac{1}{1-n}\left(\frac{\partial q_{x}}{\partial x}+\frac{\partial q_{y}}{\partial y}\right)=0
$$

The sediment transport rates $q_{x}$, and $q_{y}$ are complex functions of several parameters, including waves, currents, water depth, density, and sediment properties (including grain size and porosity). Here, we assume the sediment properties and water level are fixed in every time step. Under these assumptions, the sediment transport rates caused by waves and currents can be calculated using the formula obtained through experimentation or theory. The experimental results of alongshore and offshore transport rate suggested by Chiang et al. [5], which is applicable for Taiwan coastal areas are employed:

$$
\begin{gathered}
q_{x}=q_{c}\left(u+U_{r}\right) \\
q_{y}=q_{c}\left(v+V_{r}\right) \\
q_{c}=\left\{A_{1} f_{c}\left[\left(u+U_{r}\right)^{2}+\left(v+V_{r}\right)^{2}\right]+A_{2}\left(U_{w}{ }^{2}-U_{w c}{ }^{2}\right)\right\} / g
\end{gathered}
$$




$$
\begin{gathered}
U_{w}=\sqrt{\frac{\tau_{m}}{\rho}}=\sqrt{\frac{f_{w}}{2}} \times U_{w \max }, U_{w \max }=\frac{\pi H}{T \sinh (k h)}, \\
U_{w c}=8.41 \times d_{50}^{11 / 32} \\
f_{c}=g / C_{c}^{2} \\
f_{w}=\left\{\begin{array}{c}
0.00251 \times \exp \left(5.21 \times \exp \left(\frac{A}{k_{s}}\right)^{-0.19}\right), \frac{A}{k_{s}}>1.57 \\
0.3, \frac{A}{k_{s}} \leq 1.57 \\
A=\frac{H}{2} \sinh (k h)
\end{array}\right.
\end{gathered}
$$

where $u$ and $v$ are the depth integrated average current velocity in the $x$ - and $y$-directions, respectively; $U_{r}$ and $V_{r}$ are the average equivalent river flow velocity in the $x$ - and $y$ - directions; $A_{1}$ and $A_{2}$ are the coefficients of sediment transport due to currents and waves; $f_{c}$ and $f_{w}$ are the friction factors for mean current and wave orbital fluid motion; $U_{w}$ and $U_{\text {wmax }}$ are the shear velocity and its maximum velocity due to wave motion; $U_{w c}$ is the critical shear velocity for the inception of particle motion; $g$ is the gravitational acceleration; $C_{c}$ is the nondimensional Chezy coefficient; $d_{50}$ is the median grain diameter; $A$ is the semi-orbital excursion; $H$ is the wave height; $T$ is the wave period; $k$ is the wave number; and $h$ is the water depth.

\section{Analysis of Oscillations for Morphological Scheme}

As mentioned in the Introduction, several works have focused on controlling oscillations of coastal morphological schemes. Watanabe [43], Cayocca [4], Johnson and Zyserman [21] suggested modifying the conservation equation to consider bottom elevation changes. Following Watanabe [43], it is apparent that the sediment grains tend to move downward due to the distribution force of gravity, while the local slope becomes steep; the effect of bottom slope should be taken into account. Although the simulation of the wave-current field by hydraulic models varies with the beach transformation, the change of the sediment transport flux alone cannot be expected to completely suppress the creation of a jagged bed form profile. Modification of sediment transport rate was suggested as [43]:

$$
\begin{aligned}
& q_{x}=q_{x 0}-\varepsilon_{s}\left|q_{x 0}\right| \frac{\partial z_{b}}{\partial x} \\
& q_{y}=q_{y 0}-\varepsilon_{s}\left|q_{y 0}\right| \frac{\partial z_{b}}{\partial y}
\end{aligned}
$$

where $\varepsilon_{s}$ is a positive diffusivity constant; the value of which will be determined empirically. The second subscript " 0 " indicates sediment transport on a flat bottom.

It is noted that Watanabe [43] did not consider the influence of the cross-slope terms in the alongshore direction, but they should be included for complex bathymetries. Johnson and Zyserman [21] suggested including the cross-slope terms:

$$
\begin{aligned}
& q_{x}=q_{x 0}-\varepsilon_{x x}\left|q_{x 0}\right| \frac{\partial z_{b}}{\partial x}-\varepsilon_{x y}\left|q_{x 0}\right| \frac{\partial z_{b}}{\partial y} \\
& q_{y}=q_{y 0}-\varepsilon_{y y}\left|q_{y 0}\right| \frac{\partial z_{b}}{\partial y}-\varepsilon_{y x}\left|q_{y 0}\right| \frac{\partial z_{b}}{\partial x}
\end{aligned}
$$

where $\varepsilon_{x x}, \varepsilon_{x y}, \varepsilon_{y y}$, and $\varepsilon_{y x}$ are also positive diffusivity constants.

We substitute (12) and (13) into (2), than obtain:

$$
\begin{aligned}
& \frac{\partial z_{b}}{\partial t}+\frac{1}{1-n}\left(\frac{\partial q_{x 0}}{\partial z_{b}} \frac{\partial z_{b}}{\partial x}+\frac{\partial q_{y 0}}{\partial z_{b}} \frac{\partial z_{b}}{\partial y}\right)=\frac{\partial}{\partial x}\left[\frac{\varepsilon_{x x}\left|q_{x 0}\right|}{(1-n)} \frac{\partial z_{b}}{\partial x}\right] \\
& +\frac{\partial}{\partial y}\left[\frac{\varepsilon_{y y}\left|q_{y 0}\right|}{(1-n)} \frac{\partial z_{b}}{\partial y}\right]+\frac{\partial}{\partial x}\left[\frac{\varepsilon_{x y}\left|q_{x 0}\right|}{(1-n)} \frac{\partial z_{b}}{\partial y}\right] \\
& +\frac{\partial}{\partial y}\left[\frac{\varepsilon_{y x}\left|q_{y 0}\right|}{(1-n)} \frac{\partial z_{b}}{\partial x}\right]
\end{aligned}
$$

We can rewrite (15) as an advection-diffusion equation of bed form elevation:

$$
\begin{aligned}
\frac{\partial z_{b}}{\partial t}+ & C_{x 0} \frac{\partial z_{b}}{\partial x}+C_{y 0} \frac{\partial z_{b}}{\partial y}=\frac{\partial}{\partial x}\left[\left(\frac{\varepsilon_{x x}\left|q_{x 0}\right|}{1-n}\right) \frac{\partial z_{b}}{\partial x}\right] \\
+ & \frac{\partial}{\partial y}\left[\left(\frac{\varepsilon_{y y}\left|q_{y 0}\right|}{1-n}\right) \frac{\partial z_{b}}{\partial y}\right]+\frac{\partial}{\partial x}\left[\left(\frac{\varepsilon_{x y}\left|q_{x 0}\right|}{1-n}\right) \frac{\partial z_{b}}{\partial y}\right] \\
+ & \frac{\partial}{\partial y}\left[\left(\frac{\varepsilon_{y x}\left|q_{y 0}\right|}{1-n}\right) \frac{\partial z_{b}}{\partial x}\right]
\end{aligned}
$$

where $C_{x 0}=\frac{1}{1-n} \frac{\partial q_{x 0}}{\partial z_{b}}$, and $C_{y 0}=\frac{1}{1-n} \frac{\partial q_{y 0}}{\partial z_{b}}$

The right-hand side of (16) represents the diffusion terms. These terms show that the effect of bed slope and the value of transport rates play an important role as diffusion parameters. The stability of the morphological scheme is based on these diffusion terms under control. Consequently, these diffusivity constants $\varepsilon_{x x}, \varepsilon_{x y}, \varepsilon_{y y}$, and $\varepsilon_{y x}$ should be chosen carefully and sediment transport rates in (13) and (14) should be updated in every time step after the new bed elevation is computed. 
Long et al. [24], Hsu and Hanes [15], and Henderson et al. [14] address the appearance of wave phase-resolving sediment transport models for nearshore applications by waves and wave-driven nearshore currents. Because the wave orbital fluid motion is oscillatory in space and time, the resulting sediment transport fluxes should also be oscillatory. Unfortunately, there are no schemes that can be applied to solve the advection-diffusion conservation equation while removing the effect of the oscillation by wave orbit motion without any limiters or artificial viscosities. In this paper, we consider the application of numerical oscillation removal techniques with the simulation of bedform evolution by solving the conservation equation of sediment under wave motions and wavedriven currents, such as bed-slope feedback, oscillation and the removal in spatial and temporal discretization. The details of these techniques are shown in the following sections.

\section{Modified Bed-Slope Feedback in Morphological Models}

As mentioned before, the morphodynamic system to be calculated when coupling the hydrodynamic (waves and wavedriven currents) and sediment transport into the morphological models (governed by conservation equation of sediment) is inherently unstable. This highly non-linear system will lead to diffusion if the effect of bed-slope variations in time is not taken into account $[10,11,25]$. In the morphological model, the linear stability analysis of bed-level and quasi-steady conditions for waves and currents are assumed. The waves and currents are assumed to remain unchanged during the entire calculation period, while the bathymetry does vary. Under this assumption, the sediment transport rates obtained from waves and currents remains unchanged over the same time duration. Even though the wave orbital velocity and current velocity remain unchanged, the bed level changes at every time step. This inconsistency implies that some quantities related to bed level, such as the friction factor and the sediment transport direction factor will also change.

In order to modify sediment transport with bed form slope, the down slope gravitational transport rate is the most commonly utilized while the bed-level changes are greater than a threshold value $[2,4,10,11,25,33,43]$. Consequently, the conservation equation of sediment mass coupled with the bed-slope updated terms in two-dimensions can be rewritten as:

$$
\begin{aligned}
\frac{\partial z_{b}}{\partial t} & +\frac{\partial}{\partial x}\left(q_{x 0}-\varepsilon_{x x}\left|q_{x 0}\right| \frac{\partial z_{b}}{\partial x}-\varepsilon_{x y}\left|q_{x 0}\right| \frac{\partial z_{b}}{\partial y}\right) \\
& +\frac{\partial}{\partial x}\left(q_{y 0}-\varepsilon_{y y}\left|q_{y 0}\right| \frac{\partial z_{b}}{\partial y}-\varepsilon_{y x}\left|q_{y 0}\right| \frac{\partial z_{b}}{\partial y}\right)=0
\end{aligned}
$$

We recommend that the modified bed-slope feedback should be processed at every time step. It is very effective for the removal oscillations for long term simulations.

\section{Oscillations Removal in Spatial Discretization}

In order to control the oscillations in space for the morphological model, there are several numerical schemes as reviewed by Callaghan et al. [3] and Long et al. [24]. Among these oscillation removal schemes, the NOC and WENO scheme are more stable finite-difference schemes than the others. Based on the accuracy of algorithm, the fifth order WENO scheme is used in the study.

The WENO schemes are based on the essentially nonoscillatory (ENO) schemes, which were first developed by Harten et al. [13] in the form of finite volume schemes and were later improved by Shu and Osher [37]. The ENO schemes are generalizations of the total variation diminishing (TVD) schemes of Harten [12]. The TVD schemes are designed so that the total variation of specific quantity in space remains constant or only decrease in time. During the solution process, there will be no new extrema generated. In other words, the TVD schemes typically degenerate to first-order accuracy at locations with smooth extrema, while the ENO schemes maintain high-order accuracy. The key idea of the ENO schemes is to use the smoothest stencil among several candidates to approximate the fluxes at the cell boundaries to high order and at the same time to avoid spurious oscillations near shocks and discontinuities. The WENO schemes process one step further by taking a weighted average of all candidates, and the weights are adjusted by the local smoothness.

The first version of WENO schemes was developed by Liu et al. [23] for one-dimensional conservation laws of fluid mechanics. Jiang and Shu [19] applied the scheme to multidimensional cases with a new weighting procedure to obtain optimized accuracy. Later, Jiang and $\mathrm{Wu}$ [20] extended a high-order $\left(5^{\text {th }}\right)$ accurate WENO finite difference scheme, which has successfully attained comparable accuracy with fewer time-steps in computations. Shao et al. [35] first applies the WENO scheme to solve the one-dimensional conservation equation of sediment mass and study the evolution of periodic sand bars in the presence of waves at the resonant Bragg frequency. Long et al. [24] use the Euler-WENO schemes, based on first order explicit time discretization with the WENO scheme, to study the evolution of periodic alternating sand bars in a rectangular open channel with gravity flow, and found that it performs well.

We utilize the $5^{\text {th }}$ order WENO scheme with the morphological model to prevent oscillations from the discontinuous effects of large differential grid spacing.

\section{Oscillations Removal in Temporal Discretization}

As mentioned before, the inaccuracy of bed-level simulation in every time-step is caused by discretization errors and oscillation factors from the sub-models of waves, currents, or sediment transport rates. They will lead to diffusions and dispersions in the long term. Many algorithms have been used in the literature, such as the simple explicit/implicit method, the time-averaged multi-level method, and the predictor- 
corrector method. In this study, a two-step, three-time-level method is suggested to provide accuracy and stability for temporal discretization. This can be easily implemented in time discretization and does not lead to a significant CPU time increases.

\section{CONTROLLING OSCILLATORY MORPHOLOGICAL NUMERICAL SCHEMES}

In this section, we present detailed numerical methodologies of the high order WENO scheme and the bed-level updates in three-time-levels.

\section{WENO Schemes}

There are many studies that have applied WENO schemes in hydrodynamic and magnetodynamic conservation laws. These schemes are shown to perform well for one- or twodimensional instability problems. However, WENO schemes have not been extensively used for coastal morphodynamic instability issues.

In this subsection, we briefly present the finite difference version for the sediment conservation equation using the WENO schemes. Following the numerical algorithms of Jiang et al. [18] and the assumption of Long et al. [24], we will describe the one-dimensional problem first, and then extend to two-dimensions. To achieve numerical stability and to avoid entropy-violating solutions, upwinding and sediment flux splitting approaches are used. The sediment transport rate can be split into two parts associated with bedform propagation in the positive and negative $\mathrm{x}$ (offshore) directions. This can be written as:

$$
\begin{aligned}
& q(C)=q^{+}(C)+q^{-}(C) \\
& q^{+}=(1-n) \int_{0}^{z_{b}} C^{+}(z) d z \\
& q^{-}=(1-n) \int_{0}^{z_{b}} C^{-}(z) d z
\end{aligned}
$$

where $\mathrm{C}$ is phase velocity of the bedform and $\mathrm{C}^{+}$and $\mathrm{C}^{-}$are the phase velocities of the bedform propagating in the positive and negative $x$-directions, respectively, i.e. $C^{+}=\max (C, 0), C^{-}=$ $\min (C, 0)$. Thus,

$$
\begin{aligned}
& \frac{d q^{+}(C)}{d C} \geq 0, \text { for } C=C^{+} \\
& \frac{d q^{-}(C)}{d C} \leq 0, \text { for } C=C
\end{aligned}
$$

Following Jiang and $\mathrm{Wu}[20]$, the WENO scheme uses a conservative approximation to the spatial derivatives,

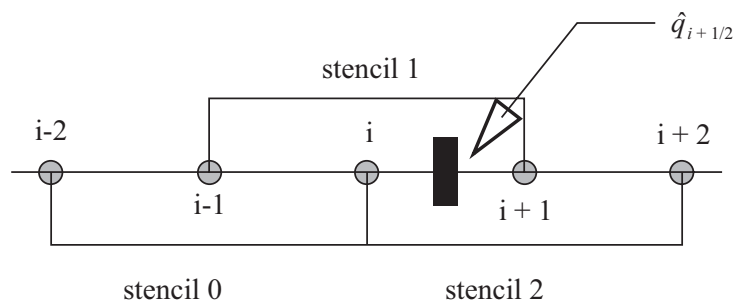

Fig. 1. The three sub-stencils with five points of WENO approximation.

$$
\frac{\partial z_{b}}{\partial t}=-\frac{\partial q}{\partial x}=-\frac{\hat{q}_{i+1 / 2}-\hat{q}_{i-1 / 2}}{\Delta x}
$$

where $\hat{q}_{i+1 / 2}$ and $\hat{q}_{i-1 / 2}$ are the approximations of the sediment transport rate at grid locations $(i+1 / 2)$ and $(i-1 / 2)$, respectively, for the three stencil system of the WENO scheme (Fig. 1).

We then apply the WENO approximation procedure, as was given in (18), to obtain two numerical fluxes, $\hat{q}_{i+1 / 2}^{ \pm}$, and sum them to obtain the numerical flux $\hat{q}_{i+1 / 2}$ :

$$
\hat{q}_{i+1 / 2}=\hat{q}_{i+1 / 2}^{-}+\hat{q}_{i+1 / 2}^{+}
$$

The left-biased-flux $\hat{q}_{i+1 / 2}^{-}$of (24) is calculated by the WENO scheme with approximations of three sub-stencils in a five point stencil system (grid positions from $i-2$ to $i+2$ in Fig. 1). The idea of the WENO scheme is to properly weight the three sub-stencils for the five points. This is written as:

$$
\hat{q}_{i+1 / 2}^{-}=\left\{\begin{array}{c}
\omega_{0} q_{i+1 / 2}^{0}+\omega_{1} q_{i+1 / 2}^{1}+\omega_{2} q_{i+1 / 2}^{2}, \\
0, \quad C_{i+1 / 2}<0
\end{array}\right.
$$

where $\omega_{s}(\mathrm{~s}=0,1$, or 2$)$ are the positive weights, and $q_{i+1 / 2}^{s}$ ( $s=0,1$, or 2 ) are the approximations of the sub-stencils.

In each sub-stencil $s(s=0,1$, or 2$)$, the $3^{\text {rd }}$-order accurate approximation $q_{i+1 / 2}^{S}$ is obtained by the Taylor series expansion as:

$$
\begin{aligned}
& q_{i+1 / 2}^{0}=\frac{1}{3} q_{i-2}-\frac{7}{6} q_{i-1}+\frac{11}{6} q_{i} \\
& q_{i+1 / 2}^{1}=-\frac{1}{6} q_{i-1}+\frac{5}{6} q_{i}+\frac{1}{3} q_{i+1} \\
& q_{i+1 / 2}^{2}=\frac{1}{3} q_{i}+\frac{5}{6} q_{i+1}-\frac{1}{6} q_{i+2}
\end{aligned}
$$

The WENO scheme procedure of three sub-stencils with the five point system possesses the following properties in (25): first, the approximation $\hat{q}_{i+1 / 2}$ at grid position $i+1 / 2$ is accurate to the fifth-order; and second, no Gibbs phenomena occur (i.e., spurious oscillations), while $\hat{q}_{i+1 / 2}$ is discontinuous near $i+1 / 2$. 
In accordance with the above two properties, Jiang and Shu with [19] suggested the calculation of weights as:

$$
\begin{aligned}
& \omega_{0}=\frac{\alpha_{0}}{\alpha_{0}+\alpha_{1}+\alpha_{2}} \\
& \omega_{1}=\frac{\alpha_{1}}{\alpha_{0}+\alpha_{1}+\alpha_{2}} \\
& \omega_{2}=\frac{\alpha_{2}}{\alpha_{0}+\alpha_{1}+\alpha_{2}}
\end{aligned}
$$

where the coefficients $\alpha_{0}, \alpha_{1}, \alpha_{2}$ are calculated by Long et al. [24]:

$$
\begin{aligned}
& \alpha_{0}=\frac{0.1}{\left(\varepsilon+I S_{0}\right)^{2}} \\
& \alpha_{1}=\frac{0.6}{\left(\varepsilon+I S_{1}\right)^{2}} \\
& \alpha_{2}=\frac{0.3}{\left(\varepsilon+I S_{2}\right)^{2}}
\end{aligned}
$$

In which $\varepsilon \approx 10^{-20}$ is used to prevent the denominators of (32)-(34) from becoming zero, and the smoothness measurements are written as:

$$
\begin{gathered}
I S_{0}=\frac{13}{12}(a-b)^{2}+\frac{1}{4}(a-3 b)^{2} \\
I S_{1}=\frac{13}{12}(b-c)^{2}+\frac{1}{4}(b+c)^{2} \\
I S_{2}=\frac{13}{12}(c-d)^{2}+\frac{1}{4}(3 c-d)^{2}
\end{gathered}
$$

where

$$
\begin{gathered}
a=q_{i-2}-q_{i-1} \\
b=q_{i-1}-q_{i} \\
c=q_{i}-q_{i+1} \\
d=q_{i+1}-q_{i+2}
\end{gathered}
$$

Similarly, we can give the right-biased-flux $\hat{q}_{i+1 / 2}^{+}$of (24) in the same procedure.

$$
\hat{q}_{i+1 / 2}^{+}=\left\{\begin{array}{c}
\tilde{\omega}_{0} \tilde{q}_{i+1 / 2}^{0}+\tilde{\omega}_{1} \tilde{q}_{i+1 / 2}^{1}+\tilde{\omega}_{2} \tilde{q}_{i+1 / 2}^{2}, \quad C_{i+1 / 2}<0 \\
0, \quad C_{i+1 / 2} \geq 0
\end{array}\right.
$$

$$
\begin{aligned}
& \tilde{q}_{i+1 / 2}^{0}=-\frac{1}{6} q_{i-1}+\frac{5}{6} q_{i}+\frac{1}{3} q_{i+1} \\
& \tilde{q}_{i+1 / 2}^{1}=\frac{1}{3} q_{i}+\frac{5}{6} q_{i+1}-\frac{1}{6} q_{i+2} \\
& \tilde{q}_{i+1 / 2}^{2}=\frac{11}{6} q_{i+1}-\frac{7}{6} q_{i+2}+\frac{1}{3} q_{i+3}
\end{aligned}
$$

$$
\tilde{\omega}_{0}=\frac{\tilde{\alpha}_{0}}{\tilde{\alpha}_{0}+\tilde{\alpha}_{1}+\tilde{\alpha}_{2}}
$$

$$
\tilde{\omega}_{1}=\frac{\tilde{\alpha}_{1}}{\tilde{\alpha}_{0}+\tilde{\alpha}_{1}+\tilde{\alpha}_{2}}
$$

$$
\tilde{\omega}_{2}=\frac{\tilde{\alpha}_{2}}{\tilde{\alpha}_{0}+\tilde{\alpha}_{1}+\tilde{\alpha}_{2}}
$$

$$
\tilde{\alpha}_{0}=\frac{0.1}{\left(\varepsilon+I \tilde{S}_{0}\right)^{2}}
$$

$$
\tilde{\alpha}_{1}=\frac{0.6}{\left(\varepsilon+I \tilde{S}_{1}\right)^{2}}
$$

$$
I \tilde{S}_{1}=\frac{13}{12}(c-d)^{2}+\frac{1}{4}(c+d)^{2}
$$

At the grid location $i-1 / 2$, the left-biased-flux $\hat{q}_{i-1 / 2}^{-}$can be repeated using (24)-(58) by simply shifting $i$ backward one grid. Consequently, the spatial discretization of WNEO finite 
difference scheme for one-dimensional sediment conservation problem is complete. With a simple $1^{\text {st }}$-order forward temporal discretization, Eq. (2) can be solved by the Euler-WENO scheme as:

$$
\frac{z_{b i}^{n+1}-z_{b i}^{n}}{\Delta t}+\frac{1}{1-n} \frac{\hat{q}_{i+1 / 2}-\hat{q}_{i-1 / 2}}{\Delta x}=O\left(\Delta t, \Delta x^{5}\right)
$$

The extension of the Euler-WENO scheme for (2) in twodimensions can be easily given as:

$$
\begin{aligned}
& \frac{z_{b i, j}^{n+1}-z_{b i, j}^{n}}{\Delta t}+\frac{1}{1-n} \frac{\hat{q}_{x i+1 / 2, j}^{n}-\hat{q}_{x i-1 / 2, j}^{n}}{\Delta x} \\
& +\frac{1}{1-n} \frac{\hat{q}_{y i, j+1 / 2}^{n}-\hat{q}_{y i, j-1 / 2}^{n}}{\Delta y}=O\left(\Delta t, \Delta x^{5}, \Delta y^{5}\right)
\end{aligned}
$$

\section{Bed-Level Updated Two-Steps Three-Time-Levels WENO Dcheme}

In this subsection, we improve the Euler-WENO scheme in temporal discretization by explicit two-step, three-time-level finite difference scheme and add the bed-slope feedback technique for coastal morphological model.

For one-dimensional sediment conservation problem, Eq. (59) becomes:

\section{Step 1:}

$$
\frac{z_{b i}^{n+1 / 2}-z_{b i}^{n}}{\Delta t / 2}+\frac{1}{1-n} \frac{\hat{q}\left(q_{0}, z_{b i}^{n}\right)_{i+1 / 2}-\hat{q}\left(q_{0}, z_{b i}^{n}\right)_{i-1 / 2}}{\Delta x}=0
$$

\section{Step 2:}

$$
\frac{z_{b i}^{n+1}-z_{b i}^{n}}{\Delta t}+\frac{1}{1-n} \frac{\hat{q}\left(q_{0}, z_{b i}^{n+1 / 2}\right)_{i+1 / 2}-\hat{q}\left(q_{0}, z_{b i}^{n+1 / 2}\right)_{i-1 / 2}}{\Delta x}=0
$$

This scheme is temporally accurate to the second-order with a truncation error of $O\left[\Delta t^{2}, \Delta x^{5}\right]$. This method is easily extended to two-dimensions. Thus, Eq. (60) becomes:

\section{Step 1:}

$$
\begin{gathered}
\frac{z_{b i, j}^{n+1 / 2}-z_{b i, j}^{n}}{\Delta t / 2}+\frac{1}{1-n} \frac{\hat{q}_{x}\left(q_{x 0}, z_{b i}^{n}\right)_{i+1 / 2, j}^{n}-\hat{q}_{x}\left(q_{x 0}, z_{b i}^{n}\right)_{i-1 / 2, j}^{n}}{\Delta x} \\
+\frac{1}{1-n} \frac{\hat{q}_{y}\left(q_{y 0}, z_{b i}^{n}\right)_{i, j+1 / 2}^{n}-\hat{q}_{y}\left(q_{y 0}, z_{b i}^{n}\right)_{i, j-1 / 2}^{n}}{\Delta y}=0
\end{gathered}
$$

\section{Step 2:}

$$
\frac{z_{b i, j}^{n+1}-z_{b i, j}^{n}}{\Delta t}+\frac{1}{1-n} \frac{\hat{q}_{x}\left(q_{x 0}, z_{b i}^{n+1 / 2}\right)_{i+1 / 2, j}^{n+1 / 2}-\hat{q}_{x}\left(q_{x 0}, z_{b i}^{n+1 / 2}\right)_{i-1 / 2, j}^{n+1 / 2}}{\Delta x}
$$

$$
+\frac{1}{1-n} \frac{\hat{q}_{y}\left(q_{y 0}, z_{b i}^{n+1 / 2}\right)_{i, j+1 / 2}^{n+1 / 2}-\hat{q}_{y}\left(q_{y 0}, z_{b i}^{n+1 / 2}\right)_{i, j-1 / 2}^{n+1 / 2}}{\Delta y}=0
$$

\section{Phase Celerity of the Bedform}

There is only one undetermined parameter for the bed-level updated, 2-time-step WENO scheme; namely the phase celerity of the bed form.

Equation (2) can be written as:

$$
\frac{\partial z_{b}}{\partial t}+\frac{1}{1-n}\left(\frac{\partial q_{x}}{\partial z_{b}} \frac{\partial z_{b}}{\partial x}+\frac{\partial q_{y}}{\partial z_{b}} \frac{\partial z_{b}}{\partial y}\right)=0
$$

Since the phase velocity of bedforms can be assumed as $C_{x}=1 /(1-n) \partial q_{x} / \partial z_{b}, C_{y}=1 /(1-n) \partial q_{y} / \partial z_{b}$, Eq. (65) becomes:

$$
\frac{\partial z_{b}}{\partial t}+C_{x} \frac{\partial z_{b}}{\partial x}+C_{y} \frac{\partial z_{b}}{\partial y}=0
$$

In order to calculate the phase celerity $C_{x}$ and $C_{y}$, Eq. (66) can be written in vector form and (2) is substituted into it:

$$
\vec{C}=\frac{-\frac{\partial z_{b}}{\partial t}}{\left|\nabla z_{b}\right|^{2}} \vec{\nabla} z_{b}=\frac{\vec{\nabla} \cdot \vec{q}}{(1-n)\left|\nabla z_{b}\right|^{2}} \vec{\nabla} z_{b}
$$

where vector $\vec{C}=\left(C_{x}, C_{y}\right), \vec{q}=\left(q_{x}, q_{y}\right)$.

For one-dimensional case, Eq. (67) is reduced to:

$$
C\left(z_{b}\right)=\frac{\frac{\partial q}{\partial x}}{(1-n) \frac{\partial z_{b}}{\partial x}}
$$

We can calculate the phase celerity of the bedform by solving (67) and (68) for one- and two-dimensional problems. Hudson et al. [16] suggested a central difference scheme to calculate the phase celerity for the one-dimensional case:

$$
C_{i}=\frac{q_{i+1}-q_{i-1}}{(1-n)\left(z_{b i+1}-z_{b i-1}\right)}
$$

There are some disadvantages when applying (63) to estimate phase celerity in a real coastal area. It fails when $z_{b i+1}=z_{b i-1}$, and causes significant errors when the central difference spatial grid spans sand bars, dunes, or ripples. Fortunately, the WENO scheme only requires the sign of the bedform phase celerity for split sediment transport. Long et al. [24] suggested a simple formula to calculate the sign of the phase celerity:

$$
\operatorname{sign}\left(C_{i}\right)=\operatorname{sign}\left(\left(q_{i+1}-q_{i}\right)\left(z_{b i+1}-z_{b i}\right)\right)
$$




\section{Hydraulic Modeling System}

In this study, the sediment transport rates, caused by waves and wave-driven currents, are calculated by (3)-(10). The governing equations for the wave field used here are [22]:

$$
\begin{gathered}
\frac{1}{a C_{w} C_{g}}\{(\vec{U} \cdot \vec{\nabla} a)[(\vec{U} \cdot \vec{\nabla})+(\vec{\nabla} \cdot \vec{U})]\} \\
-\frac{1}{a}\left[\nabla^{2} a+\frac{1}{C_{w} C_{g}}\left(\vec{\nabla} C_{w} C_{g} \cdot \vec{\nabla} a\right)\right]-k^{2}+|\vec{\nabla} S|^{2}=0 \\
\vec{\nabla} \cdot\left[a^{2} \sigma\left(\vec{U}+\vec{C}_{g}\right)\right]=0 \\
\frac{\partial}{\partial x}(|\vec{\nabla} S| \sin \theta)-\frac{\partial}{\partial y}(|\vec{\nabla} S| \cos \theta)=0
\end{gathered}
$$

where $a$ is the wave amplitude, $C_{w}$ is the wave celerity, $C_{g}$ is the group wave velocity, $U$ is the mean current, $\nabla$ is the gradient operator, $k$ is the wave number, $S$ is the wave phase function, and $\theta$ is the wave angle. In the surf zone, Eq. (72) is modified with energy dissipation as:

$$
\begin{aligned}
\vec{\nabla} \cdot\left[a^{2} \sigma\left(\vec{U}+\vec{C}_{g}\right)\right]=\vec{\nabla} \cdot\left[\frac{2 g}{\rho} \frac{E}{\sigma}\left(\vec{U}+\vec{C}_{g}\right)\right] \\
=-\frac{5}{8} \frac{g^{2} k_{B}}{\sigma^{2}} \frac{\tan \beta}{1+\frac{3 \gamma^{\prime 2}}{2}} \frac{1}{\sqrt{1-\frac{c^{\prime}}{\gamma^{\prime}}}} \sqrt{\frac{H_{B} / 2-c^{\prime} h_{B}}{\gamma^{\prime} h_{B}}}\left(H_{B}\right)^{2}
\end{aligned}
$$

where the subscript $B$ indicates grid position in surf zone, $E$ is the wave energy, $H$ is the wave height, $\sigma$ is angular frequency, $\rho$ is the water density, $h$ is the depth from mean water level, $c$ ' is $a / h$ in the recovery zone, and $\tan \beta$ is the slope of the beach.

The governing equations for the wave driven currents flow field are [22]:

$$
\begin{gathered}
\frac{\partial \eta}{\partial t}+\frac{\partial}{\partial x}[U(h+\eta)]+\frac{\partial}{\partial y}[V(h+\eta)]=0 \\
\frac{\partial U}{\partial t}+U \frac{\partial U}{\partial x}+V \frac{\partial U}{\partial y}=f U-g \frac{\partial \eta}{\partial x}+\frac{1}{\rho}\left(\frac{\partial \tau_{x x}}{\partial x}+\frac{\partial \tau_{y x}}{\partial y}\right) \\
+\frac{1}{\rho(h+\eta)}\left(\tau_{s x}-\tau_{b x}\right)-\frac{1}{\rho(h+\eta)}\left(\frac{\partial S_{x x}}{\partial x}+\frac{\partial S_{y x}}{\partial y}\right) \\
\frac{\partial V}{\partial t}+U \frac{\partial V}{\partial x}+V \frac{\partial V}{\partial y}=-f V-g \frac{\partial \eta}{\partial y}+\frac{1}{\rho}\left(\frac{\partial \tau_{x y}}{\partial x}+\frac{\partial \tau_{y y}}{\partial y}\right) \\
+\frac{1}{\rho(h+\eta)}\left(\tau_{s y}-\tau_{b y}\right)-\frac{1}{\rho(h+\eta)}\left(\frac{\partial S_{x y}}{\partial x}+\frac{\partial S_{y y}}{\partial y}\right)
\end{gathered}
$$

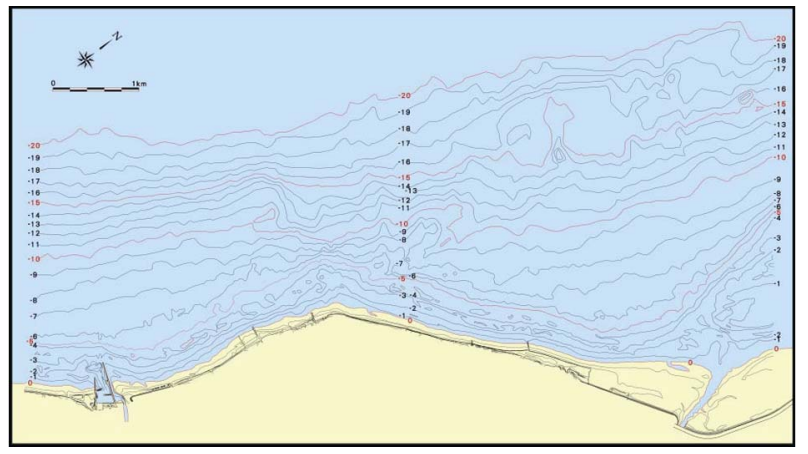

Fig. 2. The modeling area of example 1 at Miao-Li county coastal area of western Taiwan.

where $U$ and $V$ are depth-integrated-averaged flow velocities, $\eta$ is the elevation, $f$ is the Coriolis force coefficient, $\tau_{x x}$, $\tau_{x y}, \tau_{y x}, \tau_{y y}$ are the Reynolds stresses, $\tau_{s x}, \tau_{s y}$ are the wind shear stresses on the surface, $\tau_{b x}, \tau_{b y}$ are the bottom friction stresses, and $S_{x x}, S_{x y}, S_{y x}, S_{y y}$ are the radiation stresses (timeaveraged residual wave momentum fluxes).

\section{RESULTS AND DISCUSSION}

\section{Example 1: Miao-Li Coastal Area in Western Taiwan}

\section{1) Environmental Conditions}

The developed model is first applied for the complex topography in the Miao-Li county coastal area of western Taiwan. The simulation area (Fig. 2) is a sandy beach, which is $7.0 \mathrm{~km}$ long in the alongshore direction and $3.5 \mathrm{~km}$ wide in the on-off shore direction. This amounts to a maximum depth of around $35.0 \mathrm{~m}$. The median diameter of the beach sand is $D_{50}$ $=0.25 \mathrm{~mm}$. The area also has complex beach slopes (from $1 / 10$ to $1 / 150$ ) and depth contours. The shoreline orientation is in the NNE to NW direction. The tide is semidiurnal with a mean range of around $3.0 \mathrm{~m}$. Since tidal current is negligible in the shore area, waves are the main factors in the coastal dynamics. The dominant wave is the winter northerly monsoon waves between September and March. The significant wave height $H_{1 / 3}$ is $2.5 \mathrm{~m}$ and the significant wave period $T_{1 / 3}$ $7.8 \mathrm{sec}$.

\section{2) Numerical Conditions}

In example 1, we analyze the morphodynamic evolution results by FTCS (forward time central space), Euler-WENO, and our bed-slope updated 2-step, 3-time-level WENO schemes using the same numerical conditions. The selected sediment coefficients are: $A_{1}=1.5$ and $A_{2}=2.5$. The spatial grid sizes of $\triangle x=\triangle y=10 \mathrm{~m}$ are used in all models (including the sub-models for waves and currents). The time step interval of $\triangle t=1 \mathrm{~s}$ is used for the nearshore current sub-model and $\triangle t=60 \mathrm{sec}$ for the morphological model.

\section{3) Results and Discussions}

Because we utilize a single directional regular wave to 


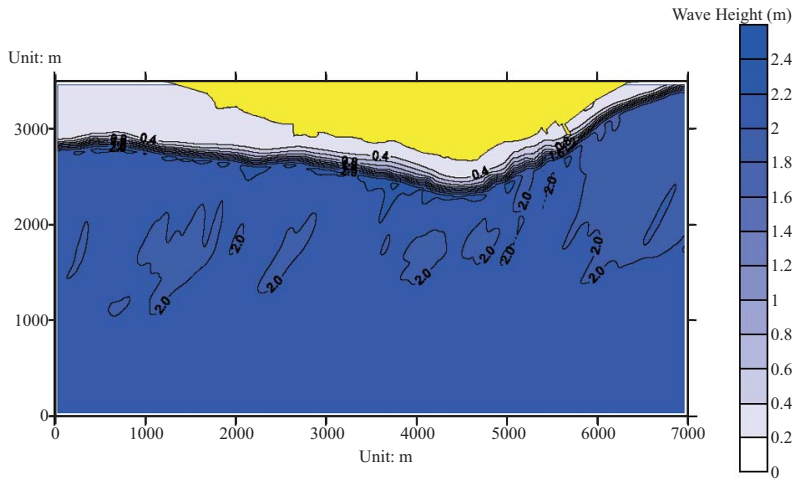

Fig. 3. The wave field of dominant monsoon waves. (unit: meter)

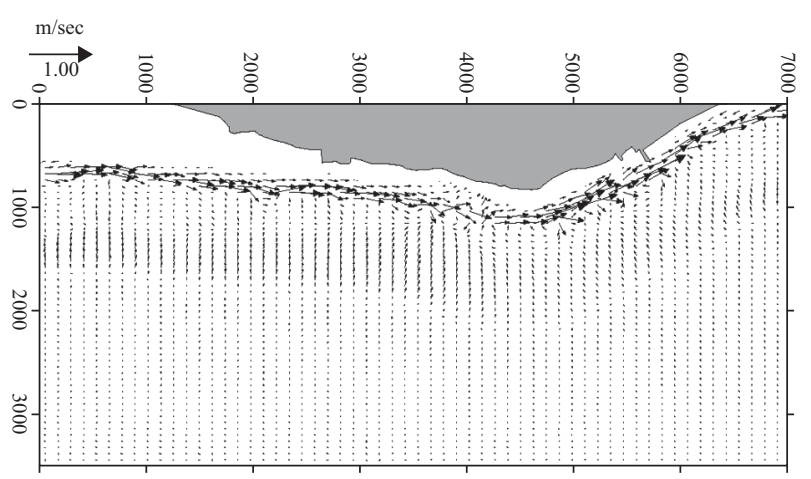

Fig. 4. The flow field of dominant monsoon waves driven currents. (unit: meter)

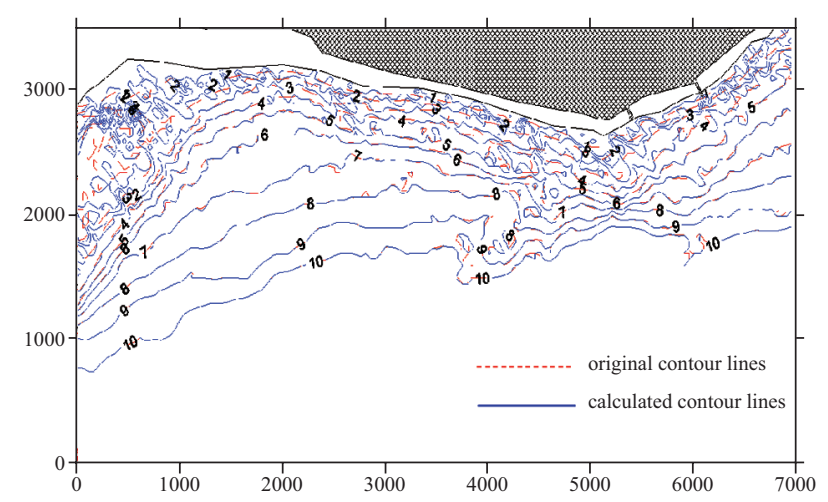

Fig. 5. The result of FTCS scheme after 90 days. (unit: meter)

represent all random sea waves, it is very difficult to accurately examine two topography surveys at different times. In order to demonstrate the oscillation removal performance, we compare our results with other schemes that have been reviewed previously. The wave field and wave-driven current flow fields are shown in Figs. 3 and 4. The morphodynamic results after 90 days using the FTCS and Euler-WENO schemes are shown in Figs. 5 and 6. The results of our morphological scheme after 30, 60, and 90 days are shown in Figs. 7, 8 and 9. We can easily see the significant differences be-

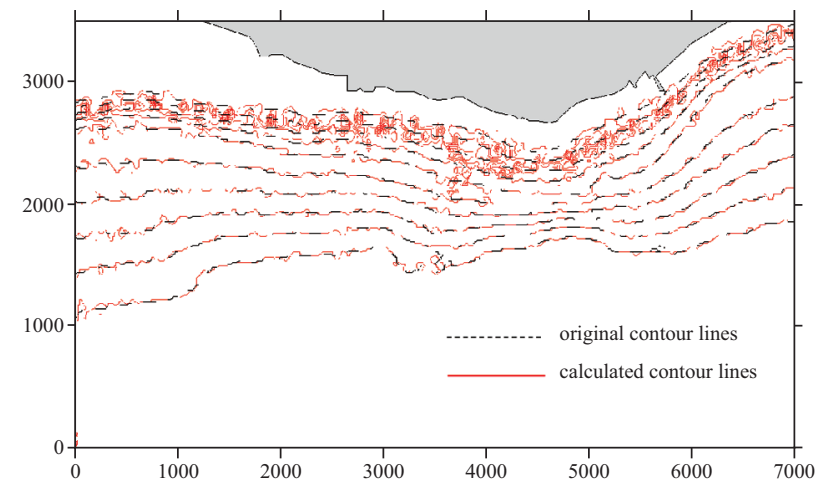

Fig. 6. The result of Euler-WENO scheme after 90 days. (unit: meter)

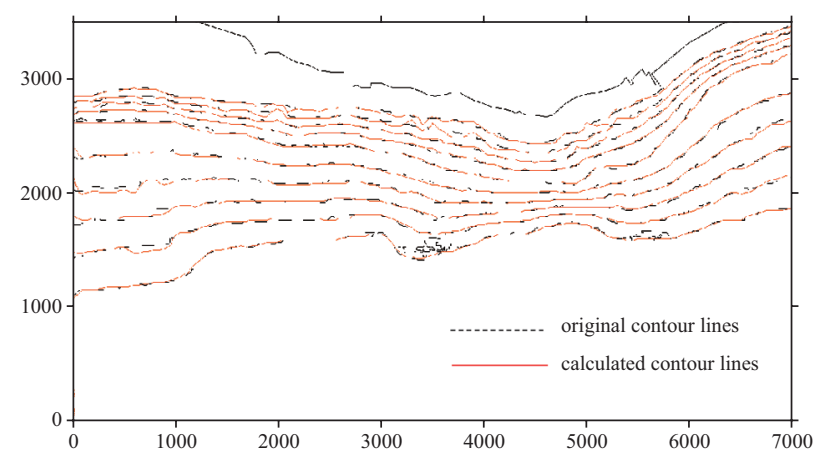

Fig. 7. The result of bed-slope updated 2-steps 3-time-levels WENO scheme after 30 days. (unit: meter)

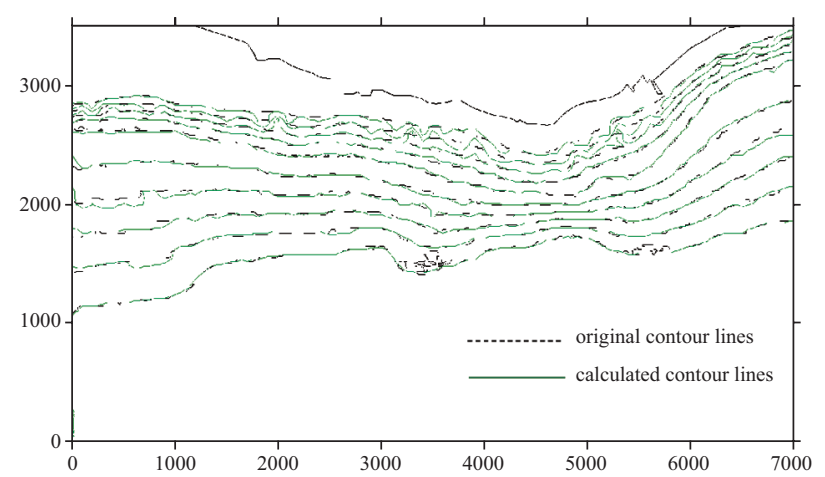

Fig. 8. The result of bed-slope updated 2-steps 3-time-levels WENO scheme after 60 days. (unit: meter)

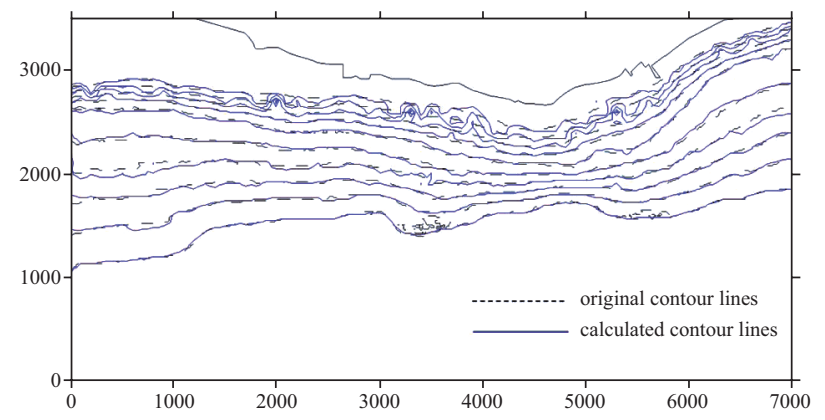

Fig. 9. The result of bed-slope updated 2-steps 3-time-levels WENO scheme after 90 days. (unit: meter) 
tween these three schemes. Our morphological scheme is more stable than the other schemes. As shown in Fig. 5, the numerical dispersion, diffusion and oscillations are clearly seen for the FTCS scheme. The results of the Euler-WENO scheme are more stable than FTCS scheme, but the diffusions still occur around $-5.0 \mathrm{~m} \sim-2.0 \mathrm{~m}$. Similar situations are also found in the wave field and wave-driven current flow field: wave breaking and maximum velocities occur in the same region, which is the steepest area of the beach. The wave breaking and the instability of the numerical scheme (such as the results of FTCS and Euler-WENO) will cause "shockwaves" in the local area. It is unreasonable for the bed-slope exceeding the rest angle of sand under water. The significance of the bed-slope updating technique and the nonlinear coupling sub-models for morphodynamic system can be clearly identified. This shows that the two-step, three-time-level method can improve the stability in the steep slopes and sharp gradients of beaches in a real coastal area.

\section{4) Stability Conditions}

The stability requirement of most morphological schemes is the Courant number $\left|C_{i} \Delta t / \Delta x\right| \leq 1$, and the large Courant numbers observed in the simulation of morphological evolutions suggest that reducing the time steps could improve the stability of the numerical schemes. However, this will increase the computational demand. Fortunately, if the diffusion terms of (16) could be properly eliminated, the limit of Courant number could be great than unity. This can be done by carefully giving the values of the diffusivity constants $\left(\varepsilon_{x x}\right.$, $\varepsilon_{x y}, \varepsilon_{y x}$, and $\varepsilon_{y y}$ ). Some diffusivity constants have been suggested for real coastal environments. Watanabe [42] suggested that the values are determined empirically through experiments. Struiksma et al. [38] and Cayocca [4] used $\varepsilon_{x x}=\varepsilon_{y y}=$ 4. However, there are few diffusivity constants available for the bed-slope updated cross-terms. To find the optimal value, trials with diffusivity of 1,2 and 4 were done for this example. We found that the optimal diffusivity constants are $\varepsilon_{x x}=\varepsilon_{y y}=$ 4 and $\varepsilon_{x y}=\varepsilon_{y x}=2$. Figures 10-13 are the results of the morphodynamic system with a spatial grid interval $\triangle x=\triangle y=$ $50 \mathrm{~m}$ after 90 days with time steps of $\triangle t=60,120,180$ and $300 \mathrm{sec}$. As can be seen, there are no differences in Figs. 10-13. Moreover, their Courant numbers are greater than one. With these methods, the modeling system is very stable and can be used with Courant numbers well above unity.

\section{Example 2: Tai-Dong Coastal Area in Eastern Taiwan}

In example 2, the Fu-Guon coastal area in Tai-Dong County in eastern Taiwan is considered (Fig. 14). The area has a steep and convex topography, which causes wave energy to concentrate. At this site, the tide is semidiurnal with a mean tidal range of less than $1 \mathrm{~m}$. The dominant wave is the summer southern monsoon waves with a significant wave height $H_{1 / 3}=$ $1.5 \mathrm{~m}$ and significant wave period $T_{1 / 3}=7.0 \mathrm{sec}$. The numerical conditions are $A_{1}=1.7, A_{2}=2.6$. The spatial grid

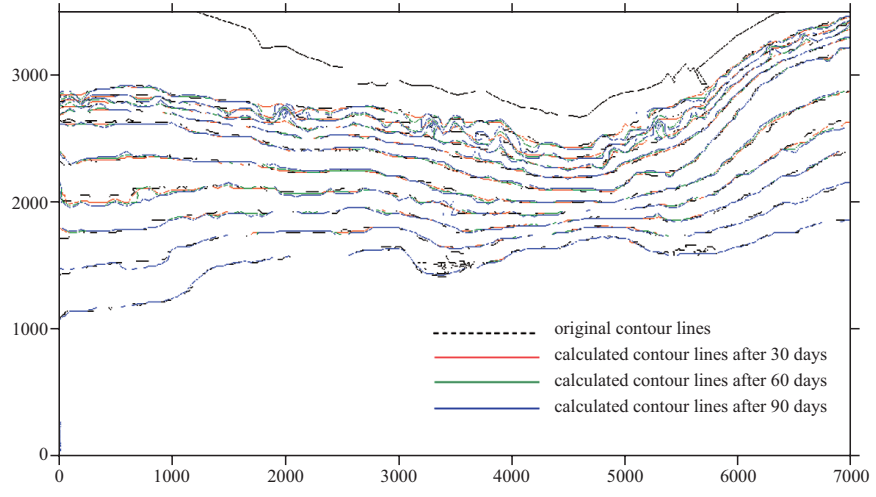

Fig. 10. The result of bed-slope updated 2-steps 3-time-levels WENO scheme with $\mathrm{dt}=60$ sec. (unit: meter)

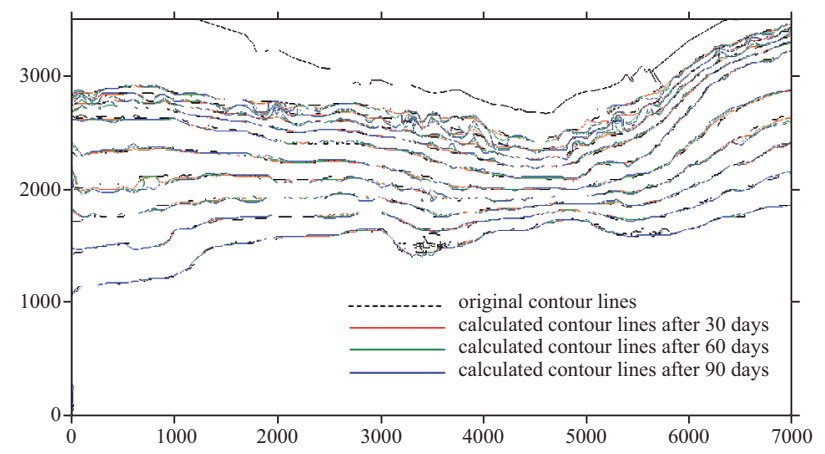

Fig. 11. The result of bed-slope updated 2-steps 3-time-levels WENO scheme with $\mathrm{dt}=120$ sec. (unit: meter)

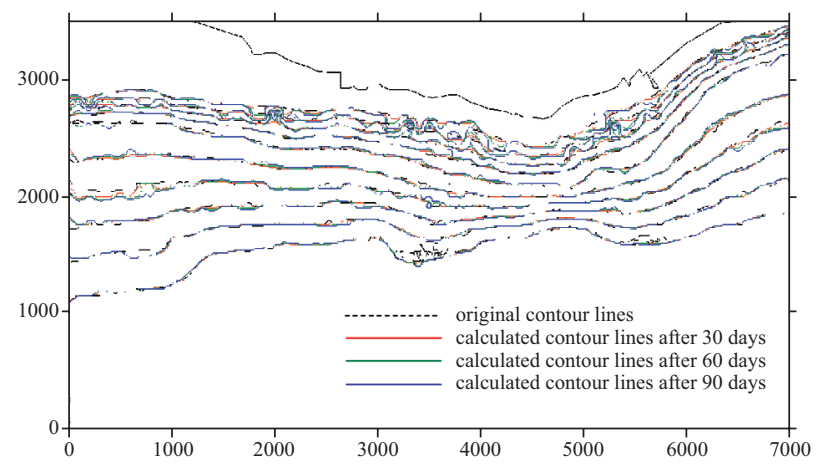

Fig. 12. The result of bed-slope updated 2-steps 3-time-levels WENO scheme with $\mathrm{dt}=180$ sec. (unit: meter)

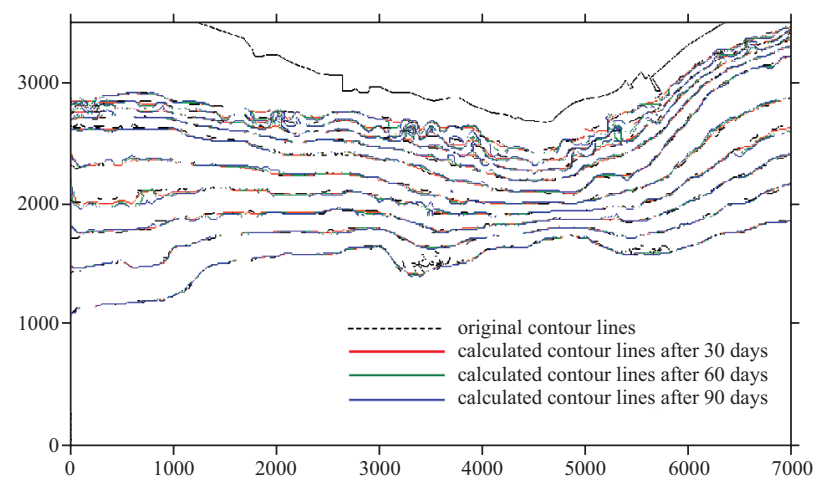

Fig. 13. The result of bed-slope updated 2-steps 3-time-levels WENO scheme with $\mathrm{dt}=\mathbf{3 0 0}$ sec. (unit: meter) 


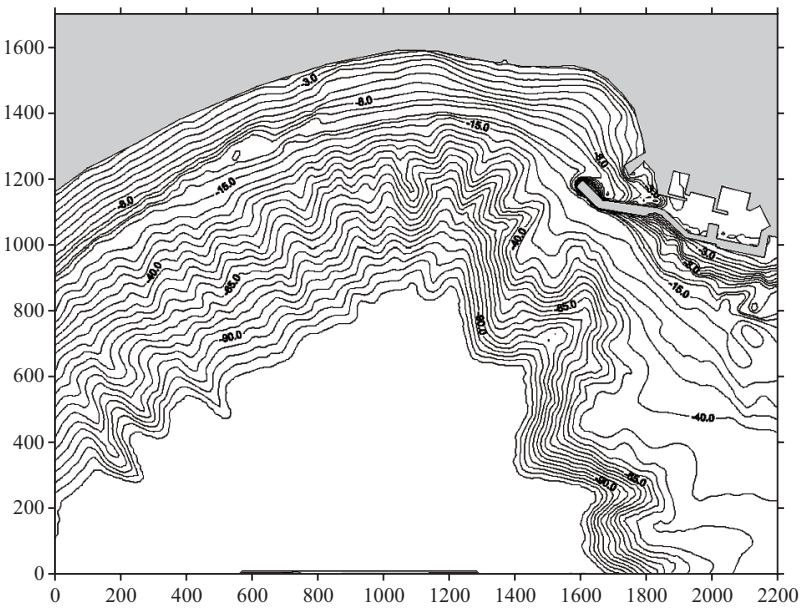

Fig. 14. The modeling area of example 2 at Ti-Dong county coastal area of eastern Taiwan. (unit: meter)

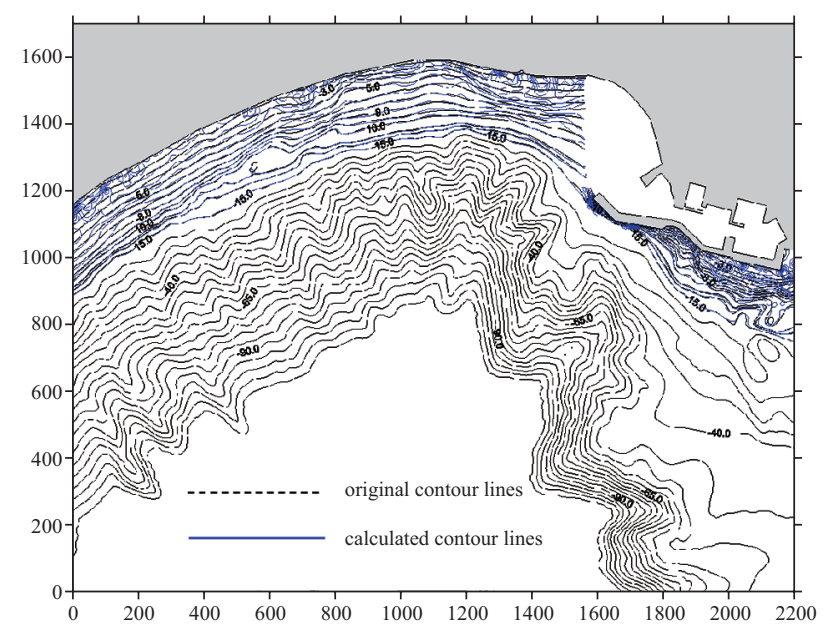

Fig. 15. The result of Euler-WENO scheme after 90 days. (unit: meter)

interval is used uniformly with $\triangle x=\triangle y=5.0 \mathrm{~m}$ in all models (including sub-models of wave and current). The time interval for the nearshore current sub-model is $\triangle t=1 \mathrm{~s}$ and $\triangle t=60$ sec for the morphological model.

The morphodynamic results of the Euler-WENO and our schemes are shown in Figs. 15 and 16. Because of the existence of underwater rigs in this area, the wave energy tends to converge at some locations and diverge at others. Consequently there are oscillations in the numerical simulation of the bed-level evolution, and our schemes are more stable than the others. This can be seen in the topography change results where wave energy was concentrated in Figs. 15 and 16.

\section{CONCLUSION}

The evolution of morphodynamic schemes for oscillation removal over the past decade are summarized, the instability of a morphological system is discussed, and numerical solu-

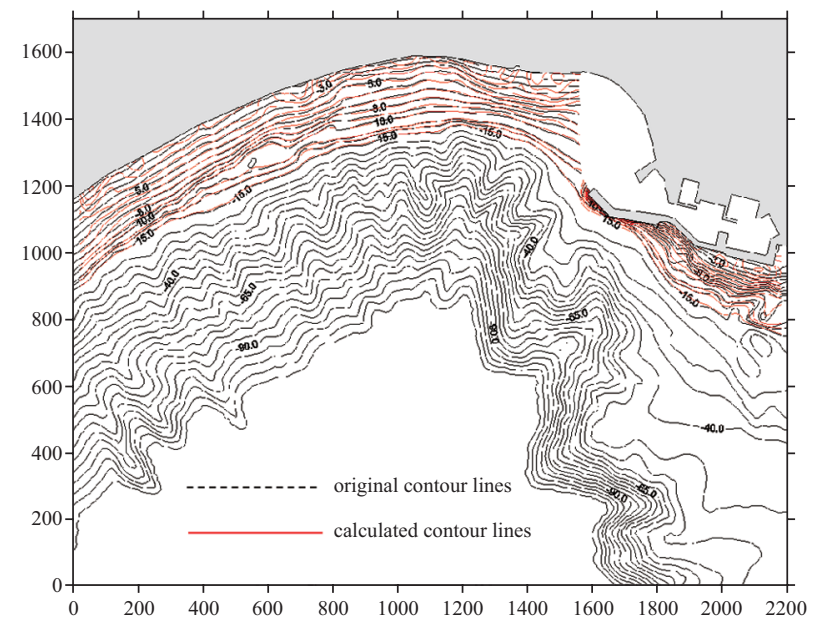

Fig. 16. The result of bed-slope updated 2-steps 3-time-levels WENO scheme after 90 days. (unit: meter)

tions of morphodynamic evolution for complex topographies are presented. The bed-slope updated 2-step, 3-time-level WENO scheme has performed well for a real coastal area subject to waves and wave- driven currents. It is sufficiently demonstrated that this scheme provides a significant improvement for shockwave capture and stability in different $\triangle t$ based on two schematized examples. Results from these two examples suggest the following: the effect of diffusions, dispersions, and oscillations from coupling the sub-models of morphodynamic systems have been improved significantly. The multi-time-level schemes for temporal discretization can improve the stability in examples with steep slopes and sharp gradients of beaches. With carefully selected diffusivity constants, the Courant number can generally exceed unity with reduced time steps efficiently for long-term simulations.

\section{REFERENCES}

1. Andersen, O. H., Hedegaard, I. B., Deigaard, R., de Girolamo, P., and Madsen, P., "Model for morphological changes under waves and current," Preprints IAHR, Symposium Suspended Sediment Transport, Florence, Italy, pp. 327-338 (1991).

2. Antunes Do Carmo, J. S., and Seabra-Santos, F. J., "Nearshore sediment dynamics computation under the combined effects of waves and currents," Advances in Engineering Software, Vol. 33, No. 1, pp. 37-48 (2002).

3. Callaghan, D. P., Saint-Cast, F., Nielsen, P., and Baldock, T. E., "Numerical solutions of the sediment conservation law; a review and improved formulation for coastal morphological modeling," Coastal Engineering, Vol. 53, pp. 557-571 (2006).

4. Cayocca, F., "Long-term morphological modeling of a tidal inlet: the Arcachon Basin, France," Coastal Engineering, Vol. 42, No. 2, pp. 115142 (2001).

5. Chiang, Y. C., Lin, M. C., and Liou, J. Y., "A model formula for estimation of the coastal sediments in west coast of Taiwan," Proceeding of the 18th Conference on Ocean Engineering in Republic of China, November 1996, pp. 619-626 (1996).

6. Coeffé, Y. and Péchon, P., "Modeling of sea-bed evolution under wave action," Proceedings of 18th International Conference on Coastal Engineering, Cape Town, South Africa (1982).

7. De Vriend, H. J., " $2 \mathrm{DH}$ mathematical modeling of morphological evolu- 
tion in shallow water," Coastal Engineering, Vol. 11, pp. 1-27 (1987).

8. De Vriend, H. J., "Analysis of 2DH morphological evolution in shallow water," Journal of Geophysical Research, Vol. 92 _C4., pp. 3877-3893 (1987).

9. De Vriend, H. J., "Two-dimensional horizontal and weakly three-dimensional models of sediment transport due to waves and currents," In: Abbott, M. B. and Price, W. A. (Eds.), Coastal, Estuarial and Harbor Engineers' Reference Book, E\&FN. Spon, London, pp. 215-238 (1994).

10. De Vriend, H. J., Capobianco, M., Chesher, T., de Swart, H. E., Latteux, B., and Stive, M. J. F., "Approaches to long-term modeling of coastal morphology: a review," Coastal Engineering, Vol. 21, pp. 225-269 (1993)

11. De Vriend, H. J., Zyserman, J., Nicholson, J., Roelvink, J. A., Péchon, P., and Southgate, H. N., "Medium term 2DH coastal area modeling," Coastal Engineering, Vol. 21, pp. 193-224 (1993).

12. Harten, A., "High resolution schemes for hyperbolic conservation laws," Journal of Computational Physics, Vol. 49, pp. 357 (1983).

13. Harten, A., Engquist, B., Osher, S., and Chakravarthy, S., "Uniformly high-order accurate essentially non-oscillatory schemes III," Journal of Computational Physics, Vol. 71, pp. 231-303 (1987).

14. Henderson, S. M., Allen, J. S., and Newberger, P. A., "Nearshore sandbar migration predicted by an eddy-diffusive boundary layer model," Journal of Geophysical Research, Vol. 109, C06024. doi:10.1029/2003JC002137 (2004).

15. Hsu, T.-J. and Hanes, D. M., "Effects of wave shape on sheet flow sediment transport," Journal of Geophysical Research, Vol. 109, C05025. doi: 10.1029/2003JC002075 (2004).

16. Hudson, J., Damgaard, J., Dodd, N., Chesher, T., and Cooper, A., "Numerical approaches for 1D morphodynamic modeling," Coastal Engineering, Vol. 52, pp. 691-707 (2005).

17. Jensen, J. H., Madsen, E. Ø., and Fredsøe, J., "Oblique flow over dredged channels: II. Sediment transport and morphology," Journal of Hydraulic Engineering, Vol. 125, No. 11, pp. 1190-1198 (1999).

18. Jiang, G.-S., Levy, D., Lin, C.-T., Osher, S., and Tadmor, E., "Highresolution nonoscillatory central schemes with nonstaggered grids for hyperbolic conservation laws," SIAM Journal on Numerical Analysis, Vol. 35, No. 6, pp. 2147-2168 (1998).

19. Jiang, G.-S. and Shu, C.-W., "Efficient implementation of weighted ENO schemes," Journal of Computational Physics, Vol. 126, No. 1, pp. 202 228 (1996)

20. Jiang, G.-S. and Wu, C.-C., "A high-order WENO finite difference scheme for the equations of ideal magnetohydrodynamics," Journal of Computational Physics, Vol. 150, pp. 561-594 (1999).

21. Johnson, H. K. and Zyserman, J. A., "Controlling spatial oscillations in bed level update schemes," Coastal Engineering, Vol. 46, pp. 109-126 (2002).

22. Lin, M. C., Kuo, J. C., Chiang, Y. C., and Liou, J. Y., "Numerical modeling of topography changes in sea region," Proceedings of the 18th Conference on Ocean Engineering in Republic of China, November 1996, pp. 627-637 (1996).

23. Liu, X.-D., Osher, S., and Chan, T., "Weighted essentially non-oscillatory schemes," Journal of Computational Physics, Vol. 115, 200 (1994).

24. Long, W., Kirby, J. T., and Shao, Z., “A numerical scheme for morphological bed level calculations," Coastal Engineering, Vol. 55, pp. 167-180 (2008).

25. Maruyama, K. and Takagi, T., "A simulation system of nearshore sediment transport for the coupling of the sea-bottom topography, waves and currents," Proceedings of the International Association of HydroEnvironment Engineering and Research, Copenhagen, Denmark, pp. 463-471 (1988).

26. Nairn, R. B. and Southgate, H. N., "Deterministic profile modeling of nearshore processes. Part 2. Sediment transport and beach profile development," Coastal Engineering, Vol. 19, No. 1-2, pp. 57-96 (1993).
27. Nicholson, J., Broker, I., Roelvink, J. A., Price, D., Tanguy, J. M., and Moreno, L., "Intercomparison of coastal area morphodynamic models," Coastal Engineering, Vol. 31, pp. 97-123 (1997).

28. O'Connor, B. A. and Nicholson, J., "Modeling changes in coastal morphology," In: Wang, S. Y. (Ed.), Sediment Transport Modeling, ASCE, pp. 160-165 (1989).

29. Roelvink, J. A., "Coastal morphodynamic evolution techniques," Coastal Engineering, Vol. 53, pp. 277-287 (2006).

30. Roelvink, J. A. and van Banning, G. K. F. M., "Design and development of Delft3D and application to coastal morphodynamics," In: Verwey, A., Minns, A. W., Babovic, V., and Maksimovic, C. (Eds.), Hydroinformatics '94, Proceedings of 1st International Conference on Hydroinformatics, Balkema, Rotterdam, The Netherlands, pp. 451-455 (1994).

31. Roelvink, J. A., Walstra, D. J. R., and Chen, Z., "Morphological modeling of Keta lagoon case," Proceeding of the 24th International Conference on Coastal Engineering, ASCE, Kobe, Japan, pp. 3223-3236 (1994).

32. Saint-Cast, F., Modelisation de la Morphodynamique des Corps Sableux en Milieu Littoral (Modeling of Coastal Sand Banks Morphodynamics), University of Bordeaux I, Ph.D. Thesis, Bordeaux, France, 245 pp (2002).

33. Saint-Cast, F., Caltagirone, J. P., and Bonneton, P., "On the splitting of the sediment fluxes balance: a new formulation for the sand waves equation," Proceeding of Coastal Engineering, Computer Modeling of Seas and Coastal Regions, Rhodes, Greece, pp. 2-12 (2001).

34. Sato, K., Shuto, N., and Tanaka, H., "Numerical simulation of thesand spit flushing at a river mouth. In: Chinese Hydraulic Engineering Society and International Research and Training Center on Erosion and Sedimentation (Ed.)," Advances In Hydro-Science and Engineering, Vol. II, Part B, Tsinghua University Press, Beijing, pp. 1399-1406 (1995).

35. Shao, Z. Y., Kim, S., and Yost, S. A., "A portable numerical method for flow with discontinuities and shocks," Proceedings of 17th Engineering Mechanics Conference, ASCE, June 13-16, Vol. 65, University of Delaware, Newark, DE, USA (on CD) (2004).

36. Shu, C.-W., "Essentially non-oscillatory and weighted essentially nonoscillatory schemes for hyperbolic conservation laws," In: Cockburn, B., Johnson, C., Shu, C. W., and Tadmor, E. (Eds.), Advanced Numerical Approximation of Nonlinear Hyperbolic Equations, Lecture Notes in Mathematics, Springer-Verlag, Berlin/New York, pp. 325-432 (1998).

37. Shu, C.-W. and Osher, S., "Efficient implementation of essentially nonoscillatory shock-capturing schemes," Journal of Computational Physics, Vol. 77, pp. 439-471 (1988).

38. Struiksma, N., Olewesen, K. W., Flokstra, C., and de Vriend, H. J., "Bed deformation in curved alluvial channels," Journal of Hydraulic Research, Vol. 23, No. 1, pp. 57-79 (1985).

39. Vincent, S. and Caltagirone, J. P., "Efficient solving method for unsteady incompressible interfacial flow problems," International Journal for Numerical Methods in Fluids, Vol. 30, No. 6, pp. 795-811 (1999).

40. Wang, Z. B., "Theoretical analysis on depth-integrated modeling of suspended sediment transport," Journal of Hydraulic Research, Vol. 30, No. 3, pp. 403-421 (1992).

41. Watanabe, A., "Numerical models of near-shore currents and beach deformation," Coastal Engineering in Japan, Vol. 25, pp. 147-161 (1982).

42. Watanabe, A., "Modeling of sediment and beach evolution," In: Horikawa, K. (Ed.), Nearshore Dynamics and Coastal Processes, University of Tokyo Press, Tokyo, Japan, pp. 292-302 (1988).

43. Watanabe, A., Maruyuma, K., Shimizu, T., and Sakakiyama, T., "Numerical prediction model of three-dimensional beach deformation around a structure," Coastal Engineering in Japan, Vol. 29, pp. 179-194 (1986).

44. Yamaguchi M. and Nishioka Y., "Numerical simulation on the change of bottom topography by the presence of coastal structures," Proceedings 19th International Conference on Coastal Engineering, ASCE, Houston, pp. 1732-1748 (1984). 